\title{
Dosage-related nature of escitalopram treatment- emergent mania/hypomania: a case series
}

This article was published in the following Dove Press journal:

Neuropsychiatric Disease and Treatment

\author{
Yasunari Yamaguchi \\ Sohei Kimoto \\ Takeshi Nagahama \\ Toshifumi Kishimoto \\ Department of Psychiatry, Nara \\ Medical University School of \\ Medicine, Kashihara, Japan
}

Correspondence: Sohei Kimoto Department of Psychiatry, Nara Medical University School of Medicine, 840 Shijyou-cho, Kashihara, Nara 634-8521, Japan

Tel +8I 74422305 I

Fax +8I 744223854

Email sohei@naramed-u.ac.jp
Objective: Several studies have documented that treatment with various antidepressant agents can result in mood switching during major depressive episodes. Escitalopram, one of the newer selective serotonin reuptake inhibitors (SSRIs), is considered preferable due to its relatively high efficacy and acceptability. Although a few cases of escitalopram treatment-emergent mania have been reported, it remains unknown whether this effect is dose-related.

Method: In the present report, we discuss three cases of treatment-emergent mania/hypomania in patients receiving escitalopram for major depressive episodes. No patients had a family or personal history of bipolar disorder.

Results: In all three cases, manic or hypomanic symptoms emerged within 1 month right after the dosage of escitalopram was increased to $20 \mathrm{mg}$ /day. Moreover, manic episodes subsided as the dosage of escitalopram was reduced. Mood switching was not observed after the cessation of escitalopram treatment.

Conclusion: Our case series indicates that escitalopram may induce treatment-emergent mania/ hypomania in a dose-related manner. Treatment at lower doses and with careful upward titration might be favorable in certain patients with bipolar depression and major depressive disorder in order to minimize the risk of mood switching.

Keywords: selective serotonin reuptake inhibitor, SSRI, escitalopram, antidepressant treatmentemergent mania/hypomania, dosage-related, bipolar depression

\section{Introduction}

Since the introduction of the first antidepressant agents, several studies have documented that treatment with such agents can result in mood switching during major depressive episodes. In fact, the major clinical guidelines ${ }^{1,2}$ grade the risk of mood switching by classifying antidepressants into groups, such as tricyclic antidepressants (TCAs), monoamine oxidase inhibitors, selective serotonin reuptake inhibitors (SSRIs), and serotonin and noradrenaline reuptake inhibitors. Although the incidence of treatment-emergent mania was reported to vary by different study designs, ${ }^{3}$ the rate of mood switching for TCAs was consistently higher than all for other antidepressants combined. ${ }^{4,5}$

Despite the importance of the phenomenon of mood switching, the precise mechanisms underlying the process have yet to be determined. However, researchers have hypothesized that antidepressant agents trigger manic/hypomanic symptoms by likely influencing the central serotonergic and catecholaminergic systems ${ }^{6-8}$ for the following reasons. First, higher levels of urinary noradrenaline ${ }^{9,10}$ and dopamine ${ }^{10,11}$ have been associated with mania and switching to mania. The concentration of certain monoamine metabolites in the cerebrospinal fluid was associated with mania symptom ratings. ${ }^{12}$ Second, direct pharmacological treatment resulting in elevated 
catecholamine levels could mimic mania-like states. ${ }^{8}$ Finally, several genetic polymorphisms linked with serotonergic and catecholaminergic systems have been proposed as putative risk factors for treatment-emergent mania/hypomania. ${ }^{13}$ Although some studies have identified various risk factors for antidepressant-induced manic switch, ${ }^{5,14-16}$ others have reported conflicting results. ${ }^{17-19}$ Notably, previous studies have suggested that antidepressant treatment-emergent mania is associated with worsened long-term outcomes, ${ }^{20}$ and that antidepressant treatment increases mood cycling in patients with bipolar disorder. ${ }^{21}$

Major depressive episodes occur in patients with both major depressive disorder and bipolar disorder. However, it is often difficult for clinicians to distinguish between the two because the clinical features of bipolar depression and major depressive disorder exhibit subtle differences. ${ }^{22,23}$ Bipolar disorder begins with a depressive episode in approximately $20 \%-70 \%$ of cases, ${ }^{24,25}$ and depressive symptoms are likely to predominate the course of the illness. ${ }^{26-28}$ Therefore, the proper use of antidepressants should be carefully considered when managing patients with major depressive episodes.

Escitalopram, one of the newer SSRIs, is a single isomer of citalopram that has recently become commercially available in Japan. Among SSRIs, escitalopram possesses the greatest serotonin transporter (5-HTT) selectivity, ${ }^{29}$ with fewer adverse effects than other SSRIs. ${ }^{30,31}$ While treatmentemergent mania/hypomania has been reported in a few clinical cases and one clinical trial, ${ }^{32-34}$ it remains unknown whether this effect is dose-related.

Consequently, the present report focuses on the doserelated properties of escitalopram treatment-emergent mania/ hypomania. As our survey of the literature failed to identify any current reports regarding dosage-related mood switching during escitalopram treatment, we believe our case series to be novel and necessary for improving our understanding of antidepressant-induced mood switching.

\section{Case presentation}

We encountered three patients who had experienced major depressive episodes without definitive risk factors for mood switching, all of whom developed manic or hypomanic symptoms during escitalopram treatment. Disease course and patient histories are described in the following sections and briefly summarized in Tables 1 and 2 .

\section{Patient A}

Patient A was a 50-year-old woman presenting with a 4-month history of depressed mood, diminished concentration, decreased motivation, and insomnia. She was not on any medications, had undergone menopause at 45 years of age, reported no history of medical comorbidities, and had not previously experienced manic or depressive episodes. She had no family history of mental illness. In addition, her thyroid gland was functioning normally (TSH: $2.68 \mu \mathrm{U} / \mathrm{mL}$, FT4: $1.14 \mathrm{ng} / \mathrm{dL}$, FT3: $2.6 \mathrm{pg} / \mathrm{mL}$ ). She was then diagnosed with major depressive disorder in accordance with criteria outlined in the fifth edition of the Diagnostic and Statistical Manual of Mental Disorders (DSM-5), ${ }^{35}$ following which she was prescribed escitalopram at a dosage of $10 \mathrm{mg} /$ day. After 14 days, she exhibited mild improvement in her depressive symptoms. However, as this effect was insufficient, the dose was increased to $20 \mathrm{mg} /$ day. After an additional 14 days, the patient developed hypomania lasting more than 4 days, exhibiting arrogant and aggressive behavior, inflated self-esteem, uncharacteristic talkative behavior and overspending, as well as a decreased need for sleep. Symptoms of hypomania improved as escitalopram was tapered off. The patient is currently stable on a treatment regimen consisting of lithium at $800 \mathrm{mg} /$ day, and she has exhibited no hypomanic symptoms since the cessation of escitalopram treatment.

\section{Patient B}

Patient B was a 66-year-old woman presenting with a 2-month history of depressed mood, anxiety, inhibition of thoughts, decreased motivation, loss of appetite, and general malaise. She had previously been diagnosed with hypertension and rheumatoid arthritis, although her physical condition had been stable for several years due to treatment with antihypertensive and immunosuppressive agents, respectively. She underwent menopause at 48 years of age, had no past history

Table I Case histories

\begin{tabular}{llll}
\hline Case & $\begin{array}{l}\text { Duration of major } \\
\text { depressive episode }\end{array}$ & $\begin{array}{l}\text { Personal and family } \\
\text { history of bipolar }\end{array}$ & $\begin{array}{l}\text { Comorbidity with medical } \\
\text { illnesses }\end{array}$ \\
\hline A. Female, age 50 & 4 months & No & No \\
B. Female, age 66 & 2 months & No & Hypertension, rheumatoid arthritis \\
C. Female, age 45 & 6 months & No & SLE \\
\hline
\end{tabular}

Abbreviation: SLE, systemic lupus erythematosus. 
Table 2 Course of escitalopram treatment-emergent mania

\begin{tabular}{|c|c|c|c|c|c|}
\hline Case & $\begin{array}{l}\text { Duration of } \\
\text { escitalopram } \\
10 \mathrm{mg} / \text { day treatment }\end{array}$ & $\begin{array}{l}\text { Duration of escitalopram } \\
20 \mathrm{mg} / \mathrm{day} \text { treatment } \\
\text { before mania }\end{array}$ & $\begin{array}{l}\text { Days before resolution of } \\
\text { mania/hypomania after } \\
\text { discontinuation of escitalopram }\end{array}$ & $\begin{array}{l}\text { Medications } \\
\text { after manial } \\
\text { hypomania }\end{array}$ & $\begin{array}{l}\text { Follow-up } \\
\text { results }\end{array}$ \\
\hline A. & I4 days & 14 days & Within 2 months & $\begin{array}{l}\text { Lithium } \\
800 \mathrm{mg} / \text { day }\end{array}$ & $\begin{array}{l}2 \text { years, no } \\
\text { hypomanic switch }\end{array}$ \\
\hline B. & I4 days & 21 days & Within I month & $\begin{array}{l}\text { Olanzapine } \\
5 \mathrm{mg} / \text { day }\end{array}$ & $\begin{array}{l}9 \text { months, no } \\
\text { manic switch }\end{array}$ \\
\hline C. & 7 days & 14 days & Within 14 days & $\begin{array}{l}\text { Sodium valproate } \\
400 \mathrm{mg} / \text { day }\end{array}$ & $\begin{array}{l}6 \text { months, no } \\
\text { hypomanic switch }\end{array}$ \\
\hline
\end{tabular}

of manic or depressive episodes, and no family history of bipolar disorder. Her thyroid gland was functioning normally (TSH: $1.90 \mu \mathrm{U} / \mathrm{mL}$, FT4 $1.26 \mathrm{ng} / \mathrm{dL}$, FT3: $2.3 \mathrm{pg} / \mathrm{mL}$ ). She was then diagnosed with major depressive disorder in accordance with criteria outlined in the DSM-5, following which she was prescribed escitalopram at a dosage of $10 \mathrm{mg} /$ day. After 14 days, she exhibited mild improvement in her depressive symptoms. However, as this effect was insufficient, the dose was increased to $20 \mathrm{mg} /$ day. Three weeks later, she developed mania lasting more than a week, characterized by hyperthymia, pressure of speech, decreased need for sleep, psychomotor agitation, flight of ideas, and inappropriate levels of irritability. Although escitalopram treatment was immediately discontinued, her manic symptoms failed to improve substantially. Therefore, she was hospitalized and temporarily managed with carbamazepine (400 mg/day), olanzapine (5 mg/day), and zotepine ( $75 \mathrm{mg} /$ day) for 1 month. Following discharge, the patient has remained stable on olanzapine only ( $5 \mathrm{mg} /$ day), and she has exhibited no hypomanic symptoms during follow-up.

\section{Patient C}

Patient $\mathrm{C}$ was a 45-year-old woman presenting with a 2-month history of depressed mood, decreased motivation, loss of appetite, and general malaise. When these symptoms emerged, the patient also developed butterfly erythema on the cheeks, at which point she received a diagnosis of systemic lupus erythematosus (SLE) and began steroid (prednisolone) treatment at $20 \mathrm{mg} / \mathrm{day}$. She had experienced a single major depressive episode without manic symptoms approximately 15 years earlier, although she had no family history of mental illness. Her menstrual cycle was regular, and thyroid gland was functioning normally (TSH: $3.66 \mu \mathrm{U} / \mathrm{mL}$, FT4: $0.97 \mathrm{ng} / \mathrm{dL}$, FT3 $2.3 \mathrm{pg} / \mathrm{mL}$ ). Depressive disorder due to medication or SLE was then suspected based on DSM- 5 criteria. The patient was first treated with venlafaxine at $37.5 \mathrm{mg} /$ day, which was increased to $187.5 \mathrm{mg}$ /day within two months. However, her depressive symptoms persisted even after the acute episode of SLE had been managed and the dose of steroids had been decreased. Therefore, venlafaxine was switched to escitalopram, following which her depressive symptoms mildly improved. Two weeks after the dose had been increased, she developed hypomania lasting more than 4 days, characterized by heightened irritability, pressure of activity, increased energy, hyperlogia, grandiosity, distractibility, and decreased need for sleep. When escitalopram was tapered off, her hypomanic symptoms significantly improved. The patient is currently stable on a treatment regimen of sodium valproate (600 mg/day) and prednisolone (20 mg/day), and she has exhibited no hypomanic symptoms during follow-up.

\section{Discussion}

To the best of our knowledge, the present case series is the first to demonstrate that escitalopram-induced mania/hypomania is most likely a dosage-related phenomenon. Indeed, in all three patients, mood switching appeared shortly after the initiation of escitalopram treatment and subsequent upward titration to the maximum dosage. Furthermore, manic episodes subsided as the dosages of escitalopram were reduced. Notably, in Patient $\mathrm{C}$, mood switching did not occur during treatment with relatively higher dosages of venlafaxine.

Recent studies have highlighted the diagnostic relevance of antidepressant-emergent mania/hypomania among patients with major depressive episodes. ${ }^{36,37}$ Indeed, certain patients with depression who develop mania or hypomania during antidepressant treatment can be diagnosed with bipolar disorder based on more recent diagnostic criteria (DSM-5), rather than with substance-induced disorder as outlined in the DSM IV-TR. ${ }^{38,39}$ Thus, although all patients were initially diagnosed with major depressive disorder or depressive disorder due to medication or physical disease, these criteria indicate that they may be diagnosed with bipolar disorder. Furthermore, our patients continued standard treatment with a mood stabilizer or atypical antipsychotics for bipolar disorder. However, some previous studies have suggested that a single 
episode of antidepressant-associated mood switching is inadequate for recommending continued treatment with mood stabilizers. ${ }^{36,40,41}$ Future studies involving larger samples are required to clarify whether treatment-induced mood switching warrants a diagnosis of bipolar disorder and subsequent, long-term treatment with mood stabilizers.

According to the Meta-Analysis of New-Generation Antidepressants (MANGA) Study Group, ${ }^{30}$ escitalopram exhibits a better efficacy-acceptability ratio than citalopram and/or other antidepressants in patients with unipolar major depression. Although it is also considered to have fewer adverse effects than other SSRIs, ${ }^{42,43}$ escitalopraminduced mania/hypomania has been documented in a few case reports and in one clinical trial..$^{32-34}$ Historically, the rate of SSRI treatment-emergent mania has been estimated at 3\%-6\% in bipolar depression and less than 3\% in major depressive disorder. ${ }^{5,6,44}$ Previous studies have identified several risk factors for antidepressant-induced manic switch, such as signs of bipolarity and family history of bipolar disorder. ${ }^{14,45-47}$ Although our case series patients who experienced treatment-emergent mania/hypomania were women during the menopausal transition, there is no consensus on gender and menopause status as potential risk factors for mood switching. ${ }^{17,47-49}$ Among women in particular, Scott et al $^{50}$ have suggested a significant relationship with thyroid disorder and family history for mood switching, although none of our patients exhibited such risk factors. In addition, some studies of newer antidepressants have reported that treatment-emergent mania/hypomania may be dose-dependent, ${ }^{51-53}$ which appears to be consistent with the present findings. Antidepressant medications are frequently prescribed for bipolar disorder, and approximately half of patients with bipolar disorder take antidepressants without mood stabilizers. ${ }^{54,55}$ Although escitalopram tolerability and efficacy have been assessed in the case of monotherapy or adjunctive therapy for bipolar depression, ${ }^{31,56}$ the dosages of escitalopram used in these previous studies were lower than those applied in our patients, suggesting that escitalopraminduced manic switching might be dose-related. Therefore, the dose-related manic switching observed in the present study may have clinical and research implications if our observations can be replicated using larger samples.

As we discussed only three cases in this report, a major limitation of our study is the small sample size. Second, we did not mention biological aspects in our cases, although several potential mechanisms have been proposed for mood switching. ${ }^{7,57,58}$ For example, previous studies have suggested that serotonin transporter gene polymorphisms (5-HTTLPR) was associated with treatment responsiveness in an ethnicitydependent manner ${ }^{59}$ or treatment-emergent hypomania/ mania $^{60}$ after receiving SSRIs. ${ }^{61}$ In addition, serotonin $2 \mathrm{~A}$ receptor (HTR2A) ${ }^{62}$ and CYP/CYP450 (CYP) ${ }^{63}$ gene functional polymorphisms have been reported to influence 5-HTT binding potential and escitalopram concentrations, respectively. Third, two of our cases had received medical treatment due to their physical disease, which might be considered as an additional factor especially given the effect of steroids on mood changes. ${ }^{64}$ However, this was unlikely to be the causative factor as their physical conditions had been stable with a fixed dosage of medicine before and after treatment-emergent mania/hypomania. Of course, we cannot exclude the possibility that a physical comorbidity or concomitant administration might be intricately involved with dose-related phenomena. Finally, it is possible that spontaneous development of manic episodes coincidentally occurred along with upward titration of escitalopram. Future studies should employ multidirectional analyses such as pharmacogenomics and imaging genetics using larger multiethnic samples to identify the correlations between dose-related escitalopram-induced mania/ hypomania and patient/illness characteristics.

\section{Conclusion}

Our case series indicates that escitalopram may induce treatment-emergent mania/hypomania in a dose-related manner. Although escitalopram is considered safer and more tolerable than other SSRIs, treatment at lower doses and with careful upward titration may be favorable in certain patients with bipolar depression and major depressive disorder in order to minimize the risk of mood switching. However, future studies involving head-to-head comparisons are required to validate this hypothesis.

\section{Acknowledgments}

We would like to thank the patients and their families for their cooperation. As we encountered these cases during regular clinical practice, the need for ethical approval and consent was waived. All patients provided written informed consent for the publication of these case reports. Data sharing was not applicable to this article, as no datasets were generated or analyzed during the current study. We did not receive any specific grant from funding agencies in the public, commercial, or not-for-profit sectors for this case series.

\section{Author contributions}

YY and TN collected data and wrote the first draft of the manuscript. SK and TK supervised the project, were critically 
involved in its design, and assisted in editing the final manuscript. All authors contributed toward drafting the paper and agree to be accountable for all aspects of the work.

\section{Disclosure}

The authors report no conflicts of interest in this work.

\section{References}

1. American Psychiatric Association. Practice guideline for the treatment of patients with bipolar disorder (revision). Am J Psychiatry. 2002;159(4 Suppl):1-50.

2. Yatham LN, Kennedy SH, Schaffer A, et al. Canadian Network for Mood and Anxiety Treatments (CANMAT) and International Society for Bipolar Disorders (ISBD) collaborative update of CANMAT guidelines for the management of patients with bipolar disorder: update 2009. Bipolar Disord. 2009;11(3):225-255.

3. Tondo L, Vázquez G, Baldessarini RJ. Mania associated with antidepressant treatment: comprehensive meta-analytic review. Acta Psychiatr Scand. 2010;121(6):404-414.

4. Gijsman HJ, Geddes JR, Rendell JM, Nolen WA, Goodwin GM. Antidepressants for bipolar depression: a systematic review of randomized, controlled trials. Am J Psychiatry. 2004;161(9):1537-1547.

5. Peet $M$. Induction of mania with selective serotonin re-uptake inhibitors and tricyclic antidepressants. Br J Psychiatry. 1994;164(4):549-550.

6. Howland RH. Induction of mania with serotonin reuptake inhibitors. J Clin Psychopharmacol. 1996;16(6):425-427.

7. Salvadore G, Quiroz JA, Machado-Vieira R, Henter ID, Manji HK, Zarate CA. The neurobiology of the switch process in bipolar disorder: a review. J Clin Psychiatry. 2010;71(11):1488-1501.

8. Kurita M. Noradrenaline plays a critical role in the switch to a manic episode and treatment of a depressive episode. Neuropsychiatr Dis Treat. 2016;12:2373-2380.

9. Post RM, Stoddard FJ, Gillin JC, et al. Alterations in motor activity, sleep, and biochemistry in a cycling manic-depressive patient. Arch Gen Psychiatry. 1977;34(4):470-477.

10. Bunney WE, Murphy DL, Goodwin FK, Borge GF. The switch process from depression to mania: relationship to drugs which alter brain amines. Lancet. 1970;1(7655):1022-1027.

11. Juckel G, Hegerl U, Mavrogiorgou P, et al. Clinical and biological findings in a case with 48-hour bipolar ultrarapid cycling before and during valproate treatment. J Clin Psychiatry. 2000;61(8):585-593.

12. Swann AC, Secunda S, Davis JM, et al. CSF monoamine metabolites in mania. Am J Psychiatry. 1983;140(4):396-400.

13. Serretti A, Artioli P, Zanardi R, et al. Genetic features of antidepressant induced mania and hypo-mania in bipolar disorder. Psychopharmacology. 2004;174(4):504-511.

14. Akiskal HS, Maser JD, Zeller PJ, et al. Switching from "unipolar" to bipolar II. An 11-year prospective study of clinical and temperamental predictors in 559 patients. Arch Gen Psychiatry. 1995;52(2):114-123.

15. Boerlin HL, Gitlin MJ, Zoellner LA, Hammen CL. Bipolar depression and antidepressant-induced mania: a naturalistic study. J Clin Psychiatry. 1998;59(7):374-379.

16. Mendhekar DN, Gupta D, Girotra V. Sertraline-induced hypomania: a genuine side-effect. Acta Psychiatr Scand. 2003;108(1):70-72.

17. Angst J. Switch from depression to mania - a record study over decades between 1920 and 1982. Psychopathology. 1985;18(2-3):140-154.

18. Visser HM, van der Mast RC. Bipolar disorder, antidepressants and induction of hypomania or mania. A systematic review. World J Biol Psychiatry. 2005;6(4):231-241.

19. Lewis JL, Winokur G. The induction of mania. A natural history study with controls. Arch Gen Psychiatry. 1982;39(3):303-306.

20. Maj M, Pirozzi R, Magliano L, Bartoli L. The prognostic significance of "switching" in patients with bipolar disorder: a 10-year prospective follow-up study. Am J Psychiatry. 2002;159(10):1711-1717.
21. Wehr TA, Goodwin FK. Rapid cycling in manic-depressives induced by tricyclic antidepressants. Arch Gen Psychiatry. 1979;36(5): 555-559.

22. Perlis RH, Brown E, Baker RW, Nierenberg AA. Clinical features of bipolar depression versus major depressive disorder in large multicenter trials. Am J Psychiatry. 2006;163(2):225-231.

23. Smith DJ, Craddock N. Unipolar and bipolar depression: different or the same? Br J Psychiatry. 2011;199(4):272-274

24. Perugi G, Micheli C, Akiskal HS, et al. Polarity of the first episode, clinical characteristics, and course of manic depressive illness: a systematic retrospective investigation of 320 bipolar I patients. Compr Psychiatry. 2000;41(1):13-18.

25. Suppes T, Leverich GS, Keck PE, et al. The Stanley Foundation Bipolar Treatment Outcome Network. II. Demographics and illness characteristics of the first 261 patients. J Affect Disord. 2001;67(1-3): 45-59.

26. Tondo L, Lepri B, Cruz N, Baldessarini RJ. Age at onset in 3014 Sardinian bipolar and major depressive disorder patients. Acta Psychiatr Scand. 2010;121(6):446-452.

27. Etain B, Lajnef M, Bellivier F, et al. Clinical expression of bipolar disorder type I as a function of age and polarity at onset: convergent findings in samples from France and the United States. J Clin Psychiatry. 2012;73(4):e561-e566.

28. Judd LL, Schettler PJ, Akiskal HS, et al. Long-term symptomatic status of bipolar I vs. bipolar II disorders. Int J Neuropsychopharmacol. 2003;6(2):127-137.

29. Owens MJ, Knight DL, NemeroffCB. Second-generation SSRIs: human monoamine transporter binding profile of escitalopram and R-fluoxetine. Biol Psychiatry. 2001;50(5):345-350.

30. Cipriani A, Furukawa TA, Salanti G, et al. Comparative efficacy and acceptability of 12 new-generation antidepressants: a multipletreatments meta-analysis. Lancet. 2009;373(9665):746-758.

31. dell'osso B, Arici C, Dobrea C, Camuri G, Benatti B, Altamura AC. Escitalopram tolerability as mono- versus augmentative therapy in patients with affective disorders: a naturalistic study. Neuropsychiatr Dis Treat. 2013;9:205-209.

32. Prapotnik M, di Pauli J, Vetter Z, König P, Conca A, Waschgler R. Antidepressant-associated mania with escitalopram. Eur Psychiatry. 2004;19(7):455-456.

33. Sharma RC. Hypomania induced by escitalopram: 2 case reports Psychopharmacol Bull. 2009;42(2):89-91.

34. Bobo WV, Grammer GG. Escitalopram-associated mania. Mil Med. 2003;168(12):ii.

35. American Psychiatric Association. Diagnostic and Statistical Manual of Mental Disorders. 5th ed. Washington, DC: APA; 2013.

36. Baldessarini RJ, Faedda GL, Offidani E, et al. Antidepressant-associated mood-switching and transition from unipolar major depression to bipolar disorder: a review. J Affect Disord. 2013;148(1): 129-135.

37. Barbuti M, Pacchiarotti I, Vieta E, et al. Antidepressant-induced hypomania/mania in patients with major depression: Evidence from the BRIDGE-II-MIX study. J Affect Disord. 2017;219:187-192.

38. Dumlu K, Orhon Z, Özerdem A, Tural U, Ulaş H, Tunca Z. Treatment-induced manic switch in the course of unipolar depression can predict bipolarity: cluster analysis-based evidence. J Affect Disord. 2011;134(1-3):91-101.

39. Terao T, Tanaka T. Antidepressant-induced mania or hypomania in DSM-5. Psychopharmacology. 2014;231(1):315.

40. Zarin DA, Pass TM. Lithium and the single episode. When to begin long-term prophylaxis for bipolar disorder. Med Care. 1987;25(12 Suppl):S76-S84.

41. Kimmel RJ, Seibert J. Is antidepressant-associated mania always an evidence of a bipolar spectrum disorder? A case report and review of the literature. Gen Hosp Psychiatry. 2013;35577(5):e571-e572.

42. Garnock-Jones KP, Mccormack PL. Escitalopram: a review of its use in the management of major depressive disorder in adults. CNS Drugs. 2010;24(9):769-796. 
43. Baldwin DS, Cooper JA, Huusom AK, Hindmarch I. A double-blind, randomized, parallel-group, flexible-dose study to evaluate the tolerability, efficacy and effects of treatment discontinuation with escitalopram and paroxetine in patients with major depressive disorder. Int Clin Psychopharmacol. 2006;21(3):159-169.

44. Benvenuti A, Rucci P, Miniati M, et al. Treatment-emergent mania/hypomania in unipolar patients. Bipolar Disord. 2008;10(6):726-732.

45. Chun BJ, Dunner DL. A review of antidepressant-induced hypomania in major depression: suggestions for DSM-V. Bipolar Disord. 2004; 6(1):32-42.

46. Truman CJ, Goldberg JF, Ghaemi SN, et al. Self-reported history of manic/hypomanic switch associated with antidepressant use: data from the Systematic Treatment Enhancement Program for Bipolar Disorder (STEP-BD). J Clin Psychiatry. 2007;68(10):1472-1479.

47. Altshuler LL, Post RM, Leverich GS, Mikalauskas K, Rosoff A, Ackerman L. Antidepressant-induced mania and cycle acceleration: a controversy revisited. Am J Psychiatry. 1995;152(8):1130-1138.

48. Koszewska I, Rybakowski JK. Antidepressant-induced mood conversions in bipolar disorder: a retrospective study of tricyclic versus non-tricyclic antidepressant drugs. Neuropsychobiology. 2009;59(1):12-16.

49. Henry C, Sorbara F, Lacoste J, Gindre C, Leboyer M. Antidepressantinduced mania in bipolar patients: identification of risk factors. J Clin Psychiatry. 2001;62(4):249-255.

50. Scott J, Brichant-Petitjean C, Etain B, et al. A re-examination of antidepressant treatment-emergent mania in bipolar disorders: evidence of gender differences. Acta Psychiatr Scand. 2017;135(5):479-488.

51. Ramasubbu R. Dose-response relationship of selective serotonin reuptake inhibitors treatment-emergent hypomania in depressive disorders. Acta Psychiatr Scand. 2001;104(3):236-239.

52. Stoner SC, Williams RJ, Worrel J, Ramlatchman L. Possible venlafaxine-induced mania. J Clin Psychopharmacol. 1999;19(2):184-185.

53. Peritogiannis V, Antoniou K, Mouka V, Mavreas V, Hyphantis TN. Duloxetine-induced hypomania: case report and brief review of the literature on SNRIs-induced mood switching. J Psychopharmacol. 2009;23(5):592-596.
54. Bottlender R, Sato T, Kleindienst N, Strauss A, Möller HJ. Mixed depressive features predict maniform switch during treatment of depression in bipolar I disorder. J Affect Disord. 2004;78(2):149-152.

55. Baldessarini R, Henk H, Sklar A, Chang J, Leahy L. Psychotropic medications for patients with bipolar disorder in the United States: polytherapy and adherence. Psychiatr Serv. 2008;59(10):1175-1183.

56. Fonseca M, Soares JC, Hatch JP, Santin AP, Kapczinski F. An open trial of adjunctive escitalopram in bipolar depression. J Clin Psychiatry. 2006;67(1):81-86.

57. Goldberg JF, Truman CJ. Antidepressant-induced mania: an overview of current controversies. Bipolar Disord. 2003;5(6):407-420.

58. Young JW, Dulcis D. Investigating the mechanism(s) underlying switching between states in bipolar disorder. Eur J Pharmacol. 2015; 759:151-162.

59. Bousman CA, Sarris J, Won ES, et al. Escitalopram efficacy in depression: a cross-ethnicity examination of the serotonin transporter promoter polymorphism. J Clin Psychopharmacol. 2014;34(5):645-648.

60. Masoliver E, Menoyo A, Pérez V, et al. Serotonin transporter linked promoter (polymorphism) in the serotonin transporter gene may be associated with antidepressant-induced mania in bipolar disorder. Psychiatr Genet. 2006;16(1):25-29.

61. Mundo E, Walker M, Cate T, Macciardi F, Kennedy JL. The role of serotonin transporter protein gene in antidepressant-induced mania in bipolar disorder: preliminary findings. Arch Gen Psychiatry. 2001; 58(6):539-544.

62. Laje G, Cannon DM, Allen AS, et al. Genetic variation in HTR2A influences serotonin transporter binding potential as measured using PET and $\left[{ }^{11} \mathrm{C}\right] \mathrm{DASB}$. Int $J$ Neuropsychopharmacol. 2010;13(6):715-724.

63. Huezo-Diaz P, Perroud N, Spencer EP, et al. CYP2C19 genotype predicts steady state escitalopram concentration in GENDEP. J Psychopharmacol. 2012;26(3):398-407.

64. Brown ES, Chandler PA. Mood and cognitive changes during systemic corticosteroid therapy. Prim Care Companion J Clin Psychiatry. 2001;3(1):17-21.
Neuropsychiatric Disease and Treatment

\section{Publish your work in this journal}

Neuropsychiatric Disease and Treatment is an international, peerreviewed journal of clinical therapeutics and pharmacology focusing on concise rapid reporting of clinical or pre-clinical studies on a range of neuropsychiatric and neurological disorders. This journal is indexed on PubMed Central, the 'PsycINFO' database and CAS,

\section{Dovepress}

and is the official journal of The International Neuropsychiatric Association (INA). The manuscript management system is completely online and includes a very quick and fair peer-review system, which is all easy to use. Visit http://www.dovepress.com/testimonials.php to read real quotes from published authors. 